\title{
STRATEGI PEMBENTUKAN KARAKTER SISWA PADA JENJANG PENDIDIKAN DASAR MELALUI MATA PELAJARAN PENDIDIKAN JASMANI OLAHRAGA DAN KESEHATAN
}

\author{
1) Akhmad Aji Pradana, IAINU Tuban, \\ email: ajiblek.id@gmail.com
}

\begin{abstract}
The rapid development of science, knowledge, technology and information systems make the impact positive and negative impact on education world. An effort to reduce the negative effect of technology appliance on education is by applying character-based education on the Elementary school students. As part of the Elementary School curriculum, a lesson called Physical Education indirectly have focus to develop the character of overall. In order to optimize the character of students through physical education, required several studies about strategy in developing character of students learning through it. Thus, this articles aims to discuss: character based education, physical education as part of character education, strategy of developing the students character through physical education learning.

This article using library research as research type. In this research, researchers collected data from various sources contained on news and articles from online journal. The selected criteria of the articles used in this research which have relevant discussion of characterbased education, physical education as part of character education, strategy of developing the students character through physical education learning.

The conclusions can be described is: 1. The students character shaping through character based education can be optimized on Elementary School Level but keep paying attention on some priciples including: Universal moral values; holistic; integrated; participatory; local wisdom; the XXI century skills; fair and inclusive; suitable with students development; and measurable. 2. The character shaping of Elementary School students can be optimized by physical education through continuous process, correct learning methods, and suitable technic and strategy. 3. The character shaping of Elementary School students through physical education can be doing with inclusive strategy.
\end{abstract}

Keywords : strategy, character shaping, physical education, Elementary School students

\section{Pendahuluan}

Perkembangan zaman merupakan hal yang tidak terelakkan, manusia selalu dituntut untuk berubah menyesuaikan terhadap setiap perubahan yang terjadi. Di era globalisasi seperti sekarang ini, perkembangan pesat terjadi di segala bidang, termasuk bidang teknologi dan informasi yang menjadi pemicu dimulainya era revolusi industri $4.0 .^{1}$ Seiring dengan perkembangan zaman ditandai dengan meningkatnya kemajuan ilmu, pengetahuan, teknologi

\footnotetext{
${ }^{1}$ Akhmad Aji Pradana, 'PENINGKATAN HASIL BELAJAR DENGAN METODE BERMAIN PERAN PADA MATA PELAJARAN BAHASA INGGRIS DI KELAS IV MI THORIQOTUL FALAH TALANGKEMBAR TAHUN PELAJARAN 2017/2018', PREMIERE : Journal of Islamic Elementary Education, 1.1 (2019), 1-17.
} 
dan sistem informasi yang menyeluruh di segala bidang, baik sosial, ekonomi, politik, seni, budaya, tak terkecuali pada bidang pendidikan. Namun demikian, perkembangan tersebut tidak hanya menimbulkan dampak positif, tetapi juga menimbulkan dampak negatif.

Dampak positif ditandai dengan semakin terbuka dan tersebarnya informasi dan pengetahuan dari dan ke seluruh dunia menembus batas ruang dan waktu. Dampak negatifnya yaitu terjadinya perubahan perilaku yang bertentangan dengan etika, norma, aturan, dan moral kehidupan yang ada pada masyarakat. ${ }^{2}$ Dalam bidang pendidikan, pemanfaatan teknologi dalam sistem pembelajaran yang bersifat virtual ataupun e-learning dapat menimbulkan sikap yang apatis pada masing-masing individu, baik bagi pelajar/siswa/mahasiswa maupun pengajar/guru/dosen. Disamping itu, Seringnya mengakses internet dikhawatirkan siswa/mahasiswa bukannya benar-benar memanfaatkan teknologi informasi dengan optimal, tetapi malah mengakses hal-hal yang tidak baik, seperti pornografi dan game online yang berlebihan. ${ }^{3}$

Berlatar belakang dari beberapa fenomena tersebut, tentu sudah semestinya kualitas pendidikan juga secara dinamis akan terus diperbaiki, dievaluasi, dan disesuaikan dengan kebutuhan di zamannya. ${ }^{4}$ Upaya pemerintah dalam menanggulangi efek negatif dari implementasi teknologi pada dunia pendidikan salah satunya adalah dengan dikembangkannya kurikulum 2013 yang sementara ini diterapkan di seluruh jenjang pendidikan formal. Kurikulum 2013 banyak menitik beratkan pada pembentukan karakter siswa yang di dalamnya banyak menekankan pada attitude (sikap) kemudian diiringi dengan skills (keterampilan), kemudian semakin tinggi jenjang pendidikan hingga Perguruan Tinggi, maka knowledge (pengetahuan) lebih dominan untuk diajarkan dari sikap dan keterampilan. ${ }^{5}$

Pembentukan kepribadian seseorang idealnya dilakukan sejak dini untuk membentuk karakter sesuai dengan yang diharapkan. Pembiasaan melakukan hal yang positif pada anak usia dini dapat membantu supaya anak menjadi insan yang sopan dan santun, baik dalam lingkungan

\footnotetext{
${ }^{2}$ Yohannes Marryono Jamun, 'Dampak Teknologi Terhadap Pendidikan', Jurnal Pendidikan Dan Kebudayaan Missio, 10.1 (2018), 48-52.

${ }^{3}$ Marryono Jamun.

${ }^{4}$ Pinton Setya Mustafa, 'Kurikulum Pendidikan Jasmani, Olahraga, Dan Kesehatan Di Indonesia Abad 21', Jurnal Pendidikan: Riset \& Konseptual, 4.3 (2020), 437-52 <https://doi.org/10.36765/jartika.v3i2.268>.

${ }^{5}$ Alnedral, Strategi Pembelajaran Pendidikan Jasmani, Olaharga Dan Kesehatan, 1st edn (Jakarta: KENCANA, 2016).
} 
sekolah, lingkungan keluarga dan lingkungan masyarakat. ${ }^{6}$ Dalam hal ini, penerapan kurikulum 2013 secara konseptual sudah sesuai dengan harapan tersebut, akan tetapi fakta di lapangan menunjukkan hasil yang jauh dari ekspektasi. Wahyuni menjelaskan dalam temuan risetnya, bahwa sebagian besar guru lebih cenderung melakukan penilaian dari aspek kognitif saja dan cenderung mengabaikan aspek afektif dan psikomotorik. ${ }^{7}$ Hal tersebut dinilai kurang sesuai dengan harapan implementasi kurikulum 2013 yang menitikberatkan pada pembentukan karakter siswa.

Upaya pembentukan karakter siswa di jenjang pendidikan dasar seharusnya menjadi prioritas utama pada implementasi K13 dalam setiap mata pelajaran. Sebagai bagian dari proses pendidikan di tingkat pendidikan formal, mata pelajaran Pendidikan Jasmani Olahraga dan Kesehatan (PJOK) mempunyai peranan penting dalam mewujudkan upaya tersebut. Salah satu peranan penting dari mata pelajaran PJOK adalah mampu menginternalisasikan nilai afektif dalam setiap pengalaman belajar melalui aktivitas olahraga. Nilai-nilai afektif seperti kejujuran, fair play, sportif, empati, simpati, berbicara santun, sikap mental yang baik, bisa dikenali sebagai bagian integral dari pendidikan jasmani dan olahraga. ${ }^{8}$ Hal tersebut menunjukkan bahwa dalam mata pelajaran PJOK yang mengimplentasikan kurikulum 2013 secara tidak langsung juga berfokus untuk pembentukan karakter secara keseluruhan mulai dari aspek kognitif, afektif, dan psikomotor. Sehingga guru perlu memahami makna dari PJOK dalam kurikulum 2013 tersebut. ${ }^{9}$ Dengan demikian pembelajaran PJOK memiliki peran yang cukup signifikan dalam membentuk kondisi fisik, pengetahuan, kepribadian siswa. ${ }^{10}$ Seiring dengan penerapan kurikulum $2013 \mathrm{di}$ jenjang pendidikan dasar di Indonesia yang terus mengalami pengembangan dalam upaya untuk mengoptimalkan pembentukan karakter siswa, maka guru PJOK perlu menyusun beberapa strategi dalam mengembangkan karakter siswa SD/MI melalui pembelajaran PJOK sesuai dengan yang diamanatkan dalam standar isi kurikulum 2013.

\footnotetext{
${ }^{6}$ Ninik Hidayati, Nurul Hakim, and M. Zakki Sulton, 'PENDIDIKAN KARAKTER MELALUI PEMBIASAAN RUTIN UNTUK MENANAMKAN NILAI - NILAI PENDIDIKAN ISLAM PADA SISWA SD/MI', PREMIERE : Journal of Islamic Elementary Education, 2.2 (2020), 47-61.

${ }^{7}$ Rina Wahyuni and Teti Berliani, 'Problematika Implementasi Kurikulum 2013 Di Sekolah Dasar', Jurnal Manajemen Dan Supervisi Pendidikan, 3.2 (2019), 63-68 <https://doi.org/10.17977/um025v3i22019p063>.

${ }^{8}$ Ermawan Susanto, 'Pembelajaran Pendidikan Jasmani Berbasis Karakter Untuk Meningkatan Nilai-Nilai Afektif Di Sekolah Dasar', Jurnal Pendidikan Karakter, 3.3 (2013), 288-301 〈https://doi.org/10.21831/jpk.v0i3.2751〉.

${ }^{9}$ Mustafa.

${ }^{10}$ Mustafa.
} 
Berdasarkan beberapa paparan di atas, maka penulisan artikel ini bertujuan untuk membahas mengenai : Pendidikan berbasis karakter, PJOK sebagai bagian dari pendidikan karakter, strategi pembentukan karakter siswa melalui pembelajaran PJOK.

\section{Metodologi}

Jenis Penelitian yang digunakan adalah studi literasi. Studi literasi merupakan jenis penelitian yng dilaksanakan dengan melakukan kajian terhadap buku, literatur, catatan, dan berbagai laporan yang berkaitan dengan masalah yang ingin dipecahkan. Dalam penelitian ini, peneliti mengumpulkan data dari berbagai sumber berupa berita online dan artikel pada jurnal online. Artikel yang dikumpulkan sebagai sumber kajian ditelusuri secara online menggunakan kata kunci pencarian "Pendidikan karakter siswa", "Strategi pembentukan karakter siswa", dan "Pembelajaran PJOK". Kriteria berita dan artikel yang dipilih yaitu artikel yang di dalamnya terdapat pembahasan yang relevan mengenai pendidikan berbasis karakter, PJOK sebagai bagian dari pendidikan karakter, dan strategi pembentukan karakter siswa melalui pembelajaran PJOK.

\section{Hasil}

\section{Pendidikan Berbasis Karakter}

Pendidikan merupakan salah satu faktor utama dalam mewujudkan kemajuan dan peningkatan kualitas hidup suatu bangsa. Dalam penyelenggaraan pendidikan, faktor pembentukan karakter dan kecakapan hidup merupakan hal yang perlu diperhatikan. Istilah karakter erat kaitannya dengan istilah akhlak, etika, dan kepribadian. Makna karakter menurut Kamus Besar Bahasa Indonesia merupakan sifat-sifat kejiwaan, akhlak atau budi pekerti yang membedakan seseorang dengan orang lain. Singkatnya, karakter merupakan sifat dan karakteristik dari diri seseorang yang terbentuk dari berbagai faktor internal maupun eksternal.

Kesuma menjelaskan bahwa pendidikan karakter adalah sebuah proses transportasi nilainilai kehidupan untuk ditumbuh kembangkan dalam kepribadian seseorang sehingga menjadi satu dalam perilaku kehidupan orang tersebut. ${ }^{11}$ Secara tidak langsung hal tersebut menunjukkan bahwa karakter seseorang bisa dibentuk melalui pendidikan yang terencana secara sistematis. Dalam ranah pendidikan formal lebih lanjut dijelaskan oleh Rosita bahwa pendidikan karakter

\footnotetext{
${ }^{11}$ Puput Widodo and Ria Lumintuarso, 'Pengembangan Model Permainan Tradisional Untuk Membangun Karakter Pada Siswa SD Kelas Atas', Jurnal Keolahragaan, 5.2 (2017), $183<$ https://doi.org/10.21831/jk.v5i2.7215>.
} 
adalah segala sesuatu yang dilakukan guru, yang mampu mempengaruhi karakter peserta didik. ${ }^{12}$ Basuki menambahkan, karakter tidak bisa dibentuk dan dibangun dalam waktu yang singkat. Pendidikan karakter membutuhkan waktu yang lama dan harus dilakukan secara berkesinambungan. ${ }^{13}$ Oleh karena itu, pendidikan karakter yang menjadi bagian dari proses pembentukan akhlak anak bangsa saat ini, diharapkan mampu menjadi fondasi utama bagi pengembangan kualitas sumber daya manusia masa datang. ${ }^{14}$ Dari beberapa uraian di atas, maka dapat dijelaskan bahwa pembentukan karakter siswa melalui pendidikan karakter dapat dioptimalkan pada jenjang pendidikan dasar karena kelak beberapa puluh tahun kedepan, mereka-mereka inilah yang akan menjadi generasi penerus kita di masa depan.

Pendidikan karakter sebenarnya sudah berlangsung sejak dahulu kala, seperti yang telah dijabarkan pada UU No 20 Tahun 2003 Tentang Sistem Pendidikan Nasional pada Pasal 3, menjelaskan bahwa pendidikan nasional berfungsi mengembangkan kemampuan dan membentuk karakter serta peradaban bangsa yang bermartabat dalam rangka mencerdaskan kehidupan bangsa. Akan tetapi seiring dengan tuntutan perubahan zaman mengharuskan adanya penyesuaian kembali internalisasi nilai-nilai di setiap proses pembelajaran. Untuk mengkaji lebih mendalam terkait konsep dasar pendidikan berbasis karakter akan dipaparkan lebih lanjut pada bagian di bawah.

\section{Tujuan Pendidikan Berbasis Karakter}

Dari beberapa uraian sebelumnya, dapat diketahui bahwa tujuan dari pendidikan berbasis karakter secara umum adalah untuk membentuk karakter seseorang sesuai dengan yang diharapkan. Akan tetapi beberapa referensi memiliki penjelasan masing-masing terkait hal ini. Dikutip dari Rosita ${ }^{15}$ Mantan Presiden RI Susilo Bambang Yudhoyono menjelaskan lebih lanjut bahwa pendidikan karakter bertujuan untuk : 1) Membentuk Manusia Indonesia yang Bermoral; 2) Membentuk Manusia Indonesia yang Cerdas dan Rasional; 3) Membentuk Manusia Indonesia yang Inovatif dan Suka Bekerja Keras; 4) Membentuk Manusia Indonesia yang optimis dan Percaya Diri; 5) Membentuk Manusia Indonesia yang Berjiwa Patriot.

\footnotetext{
${ }^{12}$ Lilis Rosita, 'PERAN PENDIDIKAN BERBASIS KARAKTER DALAM PENCAPAIAN TUJUAN PEMBELAJARAN DI SEKOLAH’, JIPSi : Jurnal Ilmu Politik Dan Komunikasi, VIII.1 (2018), 1-26.

${ }^{13}$ Sunarno Basuki, 'Prosiding Seminar Nasional PS2DM UNLAM Vol. 2 No. 2 MANAJEMEN PENGELOLAAN PENJASKES BERBASIS KARAKTER DI SEKOLAH DASAR', 2.2 (2016), 72-77.

${ }^{14}$ Alnedral.

${ }^{15}$ Rosita.
} 
Melengkapi paparan sebelumnya Nurmaidah menambahkan bahwa Tujuan pendidikan karakter adalah membentuk bangsa yang tangguh, kompetitif, berakhlak mulia, bermoral, bertoleran, bergotong royong, berjiwa patriotik, berkembang dinamis, berorientasi ilmu pengetahuan teknologi yang dijiwai oleh iman dan takwa kepada Tuhan Yang Maha Esa berdasarkan pancasila. ${ }^{16}$ Pendidikan karakter dari sisi substansi dan tujuannya identik dengan pendidikan budi pekerti, yaitu sebagai sarana untuk mengadakan perubahan secara mendasar atas individu untuk membentuk perilaku positif yang diharapkan dapat terwujud dalam perbuatan, perkataan, pikiran, sikap, perasan, dan kepribadian manusia. ${ }^{17}$

Dalam ruang lingkup yang lebih sempit, tujuan pendidikan berbasis karakter di lingkungan sekolah adalah meningkatkan mutu penyelenggaraan dan hasil pendidikan di sekolah yang mengarah pada pencapaian pembentukan karakter dan akhlak mulia siswa secara utuh, terpadu, dan seimbang sesuai dengan standard kompetensi lulusan. ${ }^{18}$ Selain itu, tujuan lain yang tidak kalah penting adalah supaya siswa dapat berubah dan memiliki karakter yang lebih baik sehingga dapat menerapkan karakter yang dimilikinya bukan hanya di sekolah saja melainkan dalam kehidupanya sehari-hari. ${ }^{19}$ Pada tahun 2016, pemerintah juga mencanangkan sebuah program bernama Penguatan Pendidikan Karakter (PPK) yang secara substantif memiliki tujuan sebagai berikut:

1) Mengembangkan platform pendidikan nasional yang meletakkan makna dan nilai karakter sebagai jiwa atau generator utama penyelenggaraan pendidikan.

2) Membangun dan membekali Generasi Emas Indonesia 2045 menghadapi dinamika perubahan di masa depan dengan keterampilan abad 21.

3) Mengembalikan pendidikan karakter sebagai ruh dan fondasi pendidikan melalui harmonisasi olah hati (etik dan spiritual), olah rasa (estetik), olah pikir (literasi dan numerasi), dan olah raga (kinestetik).

4) Merevitalisasi dan memperkuat kapasitas ekosistem pendidikan (kepala sekolah, guru, siswa, pengawas, dan komite sekolah) untuk mendukung perluasan implementasi pendidikan karakter.

\footnotetext{
${ }^{16}$ Nurmadiah, 'Konsep Dasar Pendidikan Karakter', Jurnal Al-Afkar, 6.2 (2018), 33-66.

${ }^{17}$ Syafitri Agustin Nugraha, 'KONSEP DASAR PENDIDIKAN KARAKTER', AL-MUNAWWARAH: Jurnal Pendidikan Islam, 8.2 (2016), 86-105.

${ }^{18}$ Samani, Muclas dan Hariyanto. 2011. Konsep dan Model Pendidikan Karakter. Bandung: Remaja Rosdakarya.

${ }^{19}$ Adistia Oktafiani Rusmana, 'PENERAPAN PENDIDIKAN KARAKTER DI SD', Jurnal Eduscience, 4.2 (2019), 74-80.
} 
5) Membangun jejaring pelibatan masyarakat (publik) sebagai sumber-sumber belajar di dalam dan di luar sekolah.

6) Melestarikan kebudayaan dan jati diri bangsa Indonesia dalam mendukung Gerakan Nasional Revolusi Mental (GNRM). ${ }^{20}$

Dari berbagai paparan di atas mengenai tujuan pendidikan berbasis karakter, hampir semua sumber menjelaskan maksud yang sama namun menggunakan perspektif yang berbeda. Hal lain yang dapat digaris bawahi dari uraian di atas adalah bahwa pendidikan berbasis karakter bisa dilaksanakan dimana saja, dimulai dari lingkungan keluarga, di semua jenjang pendidikan formal maupun nonformal, bahkan di ruang lingkup yang lebih luas seperti lingkungan masyarakat. Hal itu juga menekankan bahwa pembentukan karakter generasi masa depan bukan hanya tanggung jawab guru saja, melainkan merupakan tanggung jawab kita semua yang hidup di masa sekarang. Disamping itu, tujuan pendidikan karakter pada setiap jenjang pendidikan mempunyai kesamaan, yang menjadi pembeda adalah upaya pendidik dalam merealisasikan tujuan tersebut sesuai dengan jenjang pendidikan yang dimaksud.

\section{Prinsip Pendidikan Berbasis Karakter}

Implementasi pendidikan berbasis karakter di lapangan sudah banyak dilaksanakan khususnya di jenjang pendidikan dasar, namun banyak diantaranya hanya menjadi sebuah label tanpa makna dan masih belum bisa dikatakan berjalan lancar. Sebagian besar output yang dihasilkan masih saja sama dan belum optimal dalam membentuk karakter siswa sesuai dengan tujuan yang diharapkan. Rosita menjelaskan bahwa Pendidikan karakter di sekolah akan berjalan lancar jika dalam pelaksanaannya memperhatikan beberapa prinsip pendidikan karakter. ${ }^{21}$ Dalam hal ini, Kemdikbud ${ }^{22}$ telah memaparkan secara rinci beberapa prinsip pendidikan karakter yang dapat dijadikan pedoman antara lain :

1) Nilai-nilai Moral Universal

Gerakan Penguatan Pendidikan Karakter (PPK) berfokus pada penguatan nilai-nilai moral universal yang prinsip-prinsipnya dapat didukung oleh segenap individu dari berbagai macam latar belakang agama, keyakinan, kepercayaan, sosial, dan budaya.

\footnotetext{
${ }^{20}$ Kemdikbud, Kajian Dan Pedoman Penguatan Pendidikan Karakter (PPK), Kementrian Pendidikan Dan Kebudayaan Republik Indonesia, 2020 <https://cerdasberkarakter.kemdikbud.go.id/?wpdmpro=buku-konsep-danpedoman-ppk>.

${ }^{21}$ Rosita.

${ }^{22}$ Kemdikbud.
} 


\section{2) Holistik}

Gerakan PPK dilaksanakansecara holistik, dalam arti pengembangan fisik (olah raga), intelektual (olah pikir), estetika (olah rasa), etika dan spiritual (olah hati) dilakukan secara utuh-menyeluruh dan serentak, baik melalui proses pembelajaran intrakurikuler, kokurikuler, dan ekstrakurikuler, berbasis pada pengembangan budaya sekolah maupun melalui kolaborasi dengan komunitas-komunitas di luar lingkungan pendidikan.

3) Terintegrasi

Gerakan PPK sebagai poros pelaksanaan pendidikan nasional terutama pendidikan dasar dan menengah dikembangkan dan dilaksanakan dengan memadukan, menghubungkan, dan mengutuhkan berbagai elemen pendidikan, bukan merupakan program tempelan dan tambahan dalam proses pelaksanaan pendidikan.

4) Partisipatif

Gerakan PPK dilakukan dengan mengikutsertakan dan melibatkan publik seluas-luasnya sebagai pemangku kepentingan pendidikansebagai pelaksana Gerakan PPK. Kepala sekolah, pendidik, tenaga kependidikan, komite sekolah, dan pihak-pihak lain yang terkait dapat menyepakati prioritas nilai-nilai utama karakter dan kekhasan sekolah yang diperjuangkan dalam Gerakan PPK, menyepakati bentuk dan strategi pelaksanaan Gerakan PPK, bahkan pembiayaan Gerakan PPK.

5) Kearifan Lokal

Gerakan PPK bertumpu dan responsif pada kearifan lokal nusantara yang demikian beragam dan majemuk agar kontekstual dan membumi. Gerakan PPK harus bisa mengembangkan dan memperkuat kearifan lokal nusantara agar dapat berkembang dan berdaulat sehingga dapat memberi indentitas dan jati diri peserta didik sebagai bangsa Indonesia.

\section{6) Kecakapan Abad XXI}

Gerakan PPK mengembangkan kecakapan-kecakapan yang dibutuhkan oleh peserta didik untuk hidup pada abad XXI, antara lain kecakapan berpikir kritis (critical thinking), berpikir kreatif (creative thinking), kecakapan berkomunikasi (communication skill), termasuk penguasaan bahasa internasional, dan kerja sama dalam pembelajaran (collaborative learning).

7) Adil dan Inklusif 
Gerakan PPK dikembangkan dan dilaksanakan berdasarkan prinsip keadilan, nondiskriminasi, non-sektarian, menghargai kebinekaan dan perbedaan (inklusif), dan menjunjung harkat dan martabat manusia.

8) Selaras dengan Perkembangan Peserta Didik

Gerakan PPK dikembangkan dan dilaksanakan selaras dengan perkembangan peserta didik baik perkembangan biologis, psikologis, maupun sosial, agar tingkat kecocokan dan keberterimaannya tinggi dan maksimal. Dalam hubungan ini kebutuhan-kebutuhan perkembangan peserta didik perlu memperoleh perhatian intensif.

9) Terukur

Gerakan PPK dikembangkan dan dilaksanakan berlandaskan prinsip keterukuran agar dapat dimati dan diketahui proses dan hasilnya secara objektif. Dalam hubungan ini komunitas sekolah mendeskripsikan nilai-nilai utama karakter yang menjadi prioritas pengembangan di sekolah dalam sebuah sikap dan perilaku yang dapat diamati dan diukur secara objektif; mengembangkan program-program penguatan nilai-nilai karakter bangsa yang mungkin dilaksanakan dan dicapai oleh sekolah; dan mengerahkan sumber daya yang dapat disediakan oleh sekolah dan pemangku kepentingan pendidikan.

Seluruh prinsip di atas akan sangat bermakna apabila diimplementasikan dengan maksimal, tentu saja hal ini membutuhkan kerjasama dan koordinasi berbagai berbagai pihak secara konsisten dan berkelanjutan.

\section{Mata Pelajaran PJOK Sebagai Bagian dari Pendidikan Karakter}

Upaya untuk mensukseskan pendidikan karakter merupakan tanggung jawab kita bersama. Kemdikbud ${ }^{23}$ memaparkannya dalam prinsip utama dalam penyelenggaraan Gerakan PPK dilakukan dengan mengikutsertakan dan melibatkan publik seluas-luasnya sebagai pemangku kepentingan pendidikan.

Pada tingkat satuan pendidikan, gerakan pembudayaan nilai-nilai afektif dilakukan terintegrasi dengan proses kegiatan belajar mengajar (KBM) pada setiap mata pelajaran, melalui pembiasaan pada kehidupan sehari-hari. ${ }^{24}$ Dalam hal ini mata pelajaran Pendidikan Jasmani Olahraga dan Kesehatan (PJOK) juga mempunyai peranan yang sama pentingnya dengan mata

\footnotetext{
23 Kemdikbud.

${ }^{24}$ Susanto.
} 
pelajaran yang lain dalam ruang lingkup internalisasi pendidikan berbasis karakter di dalamnya. Selama ini, masyarakat berasumsi bahwa mata pelajaran PJOK identik dengan pembelajaran berbasis keterampilan olahraga, padahal pembelajaran penjas yang sarat akan aspek psikomotor di dalam pembelajarannya bukan berarti melupakan aspek afektif untuk terus ditanamkan. ${ }^{25}$ Pelaksanaan pendidikan jasmani sering terjebak dengan tujuan akhir untuk kesehatan dan kebugaran jasmani peserta didik. Tetapi di sisi lain Pendidikan Jasmani merupakan salah satu media promosi gaya hidup aktif, penanaman nilai-nilai moral, etika, dan sikap sportif. ${ }^{26}$ Endriani menambahkan bahwa Pendidikan jasmani sebagai alat untuk membantu siswa mengembangkan sosial emosional dan akhirnya dapat menumbuhkan karakter bermutu lainnya. ${ }^{27}$

Beberapa riset terkait juga membuktikan bahwa mata pelajaran PJOK merupakan salah satu media yang dapat diintegrasikan dengan pendidikan berbasis karakter dengan sangat baik. Beberapa diantaranya seperti penelitian Widodo ${ }^{28}$ yang menunjukkan bahwa model permainan tradisional pada mata pelajaran penjas dapat mengembangkan karakter siswa dan model yang dikembangkan sesuai dengan karakteristik dan pembelajaran penjas; Penelitian Susanto ${ }^{29}$ yang menghasilkan temuan bahwa desain model pembelajaran karakter yang dapat diintegrasikan dalam mata pelajaran pendidikan jasmani di sekolah dapat diterapkan dalam bentuk modul pembelajaran penjas karakter dan dapat dilaksanakan dalam ujicoba skala luas di beberapa sekolah dasar; serta beberapa hasil riset lainnya yang perlu digali lebih dalam.

\section{Strategi Pembentukan Karakter Siswa Melalui Pembelajaran PJOK}

Pendidikan karakter khususnya di Indonesia secara umum menggunakan dua strategi pengembangan. Yaitu strategi pengembangan karakter secara makro dan strategi pengembangan karakter secara mikro. Strategi Pengembangan Karakter secara Makro artinya keseluruhan konteks perencanan dan implementasi pengembangan nilai/karakter melibatkan seluruh pemangku kepentingan pendidikan nasional. Adapun strategi pengembangan karakter pada

\footnotetext{
${ }^{25}$ Merliza Mutia, Herita Warni, and Sarmidi Sarmidi, 'Peran Guru Pendidikan Jasmani Dalam Menanamkan Karakter Keapada Peserta Didik Di Sd Negeri Atu-Atu Kecamatan Pelaihari Kabupaten Tanah Laut', Multilateral Jurnal Pendidikan Jasmani Dan Olahraga, 18.2 (2019), 120-25 <https://doi.org/10.20527/multilateral.v18i2.7623>.

${ }^{26}$ Susanto.

${ }^{27}$ Dewi Endriani, Indah Verawati, and Andarias Ginting, 'Identifikasi Pembelajaran Pendidikan Jasmani Untuk Membentuk Karakter Siswa Sekolah Dasar', Jurnal Prestasi, 1.1 (2017), 1-5

<https://doi.org/10.24114/jp.v1i1.6490>.

${ }^{28}$ Widodo and Lumintuarso.

${ }^{29}$ Susanto.
} 
kontek mikro berlangsung dalam kontek satuan pendidikan atau sekolah secara holistic (the whole school reform). Sekolah sebagai leading sector, berupaya memanfaatkan dan memberdayakan semua lingkungan belajar yang ada untuk menginisiasi, memperbaiki, menguatkan dan menyempurnakan secara terus menerus proses pendidikan karakter di sekolah. ${ }^{30}$

Delapan tahun yang lalu, pemerintah mulai merancang dan memberlakukan kurikulum 2013 yang diharapkan mampu mengembangkan karakter siswa di sekolah. Dalam implementasinya, kurikulum 2013 sangat menekankan aspek karakter dalam setiap mata pelajaran. Sebagai bagian dari kurikulum di jenjang pendidikan formal, mata pelajaran PJOK juga diharuskan untuk mengintegrasikan pendidikan karakter di dalamnya.

Dalam ruang lingkup pembelajaran PJOK, Guru PJOK bertanggung jawab dalam membentuk karakter siswanya dengan berbagai aktivitas pendidikan jasmani dengan mengutamakan nilai-nilai karakter di dalamnya, tidak hanya kemampuan motoriknya saja. ${ }^{31}$ Disisi lain, dalam konteks pembelajaran Pendidikan Jasmani Olahraga dan Kesehatan (PJOK) telah dikembangkan berbagai model pembelajaran yang dapat mengembangkan ranah afektif (karakter) tersebut. Beberapa diantaranya : model Pembelajaran Tanggung Jawab Pribadi dan Sosial (TPSR) dari Hellison (2003); Model Pendidikan Olahraga yang dikembangkan oleh Siedentop dkk (2004); Model Pembelajaran Kooperatif (Dyson; 2001), Mengajar Nilai dari Lumpkin (2008), Mengajar Rasa Hormat dari Strans and Ruder (1996), dan lain-lain. ${ }^{32}$ Marten $^{33}$ menambahkan, nilai-nilai moral yang terkandung dalam aktivitas olahraga dapat dilihat dalam tabel di bawah :

Tabel 1. nilai moral yang terkandung dalam aktivitas olahraga

\begin{tabular}{|c|c|c|}
\hline Nilai Moral & Praktik Dalam Olahraga & Praktik Dalam Kehidupan \\
\hline Rasa Hormat & $\begin{array}{l}>\text { Hormat pada aturan main. } \\
>\text { Hormat pada lawan. } \\
>\text { Hormat pada kemenangan dan } \\
\text { kekalahan. }\end{array}$ & $\begin{array}{l}>\text { Hormat pada orang lain. } \\
>\text { Hormat pada lingkungan. } \\
>\text { Hormat pada diri sendiri. }\end{array}$ \\
\hline Tanggung Jawab & $\begin{array}{l}\text { Mempersiapan diri dengan baik. } \\
\text { Disiplin dalam berlatih dan } \\
\text { bertanding. } \\
\text { Kooperatif dengan sesama atlet. }\end{array}$ & $\begin{array}{l}>\text { Memenuhi kewajiban. } \\
>\text { Dapat dipercaya. } \\
>\text { Dapat mengendalikan diri. }\end{array}$ \\
\hline
\end{tabular}

\footnotetext{
${ }^{30}$ Nugraha.

${ }^{31}$ Endriani, Verawati, and Ginting.

${ }^{32}$ Susanto.

${ }^{33}$ Marten, Rainer. (2004). Successful Coaching. 3rd. ed. Champaign IL.: Human Kinetics.
} 


\begin{tabular}{|c|c|c|}
\hline Kepedulian & $\begin{array}{l}\text { Membantu teman satu tim. } \\
\text { Senang memuji dan tidak suka } \\
\text { mengritik. } \\
>\text { Bermain untuk tim. }\end{array}$ & $\begin{array}{l}>\text { Menaruh empati. } \\
>\text { Pemaaf. } \\
>\text { Murah hati. } \\
>\text { Tidak mementingkan diri } \\
\text { sendiri. }\end{array}$ \\
\hline Jujur & $\begin{array}{l}>\text { Patuh pada aturan main. } \\
\text { Setia pada tim. } \\
>\text { Mengakui kesalahan }\end{array}$ & $\begin{array}{l}\text { Memiliki ketulusan hati. } \\
>\text { Dapat dipercaya. } \\
\text { Melakukan sesuatu dengan } \\
\text { benar. }\end{array}$ \\
\hline Adil & $\begin{array}{l}\text { Tidak membeda-bedakan. } \\
\text { Memberikan kesempatan pada } \\
\text { atlet yang lain. }\end{array}$ & $\begin{array}{l}>\text { Mengikuti aturan. } \\
>\text { Toleran pada orang lain. } \\
>\text { Kesediaan berbagi. }\end{array}$ \\
\hline Beradab & $\begin{array}{l}\text { Menjadi contoh yang baik. } \\
>\text { Mendorong perilaku yang baik. } \\
>\text { Berusaha menjadi yang terbaik. }\end{array}$ & $\begin{array}{l}>\text { Patuh pada hukum dan } \\
\text { aturan. } \\
>\text { Terdidik. } \\
>\text { Bermanfaat bagi orang } \\
\text { lain. } \\
>\text { Melindungi orang lain. }\end{array}$ \\
\hline
\end{tabular}

Beberapa uraian di atas menunjukkan bahwa pembentukan karakter siswa dalam ruang lingkup pembelajaran PJOK melibatkan seluruh komponen pembelajaran yang saling berkaitan mulai dari Guru sebagai aktor utama sebagai pendesain pembelajaran, model pembelajaran, serta lingkungan tempat siswa belajar. Membangun karakter peserta didik melalui pembelajaran pendidikan jasmani olahraga dan kesehatan dapat dilaksanakan secara inklusif. Implementasi pendidikan karakter secara inklusif adalah model pendidikan karakter terintegrasikan pada semua materi yang dibawakan selama proses pembelajaran pada suatu mata pelajaran.

Sukarmin ${ }^{34}$ menjelaskan bahwa, pembentukan karakter peserta didik melalui PJOK meliputi tahap-tahap: perencanaan, pelaksanaan, dan evaluasi yang disesuaikan dengan proses pembelajaran PJOK. Uraian lebih lanjut terkait tahap-tahap tersebut dapat dideskripsikan pada bagian di bawah :

1) Perencanaan

Pada tahap ini guru PJOK mengidentifikasi nilai-nilai karakter yang akan dikembangkan dan ditanamkan pada peserta didik. Dasar pemilihan nilai karakter adalah nilai-nilai yang berhubungan erat dan mempunyai frekuensi kemunculan tinggi dalam proses pembelajaran PJOK sesuai dengan materi pembelajaran yang diajarkan. Contoh yang

\footnotetext{
${ }^{34}$ Yustinus Sukarmin, 'Membangun Karakter Peserta Didik Melalui Pembelajaran Pendidikan Jasmani Olahraga Dan Kesehatan', Seminar Nasional Pendidikan Olahraga 12 Mei 2012, 2012, 1-15.
} 
dapat diambil seperti: penanaman sikap religius pada setiap materi; penanaman sikap kepedulian, kerjasama, dan tanggung jawab pada materi permainan olahraga beregu; dan penanaman sikap kedisiplinan, kejujuran, dan percaya diri pada materi permainan olahraga individu. Tahap perencanaan meliputi juga pemilihan metode pembelajaran yang disesuaikan dengan penyampaian materi pada setiap pertemuan.

2) Pelaksanaan

Pada tahap ini dilaksanakan implementasi dari rencana yang telah disusun pada tahap sebelumnya. Setelah menentukan nilai-nilai yang akan dikembangkan dan ditanamkan pada siswa, Pada tahap ini guru PJOK melakukan tiga kegiatan untuk mendukung pemahaman peserta didik terhadap materi pembelajaran yang diajarkanmelalui kegiatan eksplorasi, elaborasi, dan konfirmasi. Pada tahap eksplorasi, guru penjasorkes memfasilitasi peserta didik agar mendapatkan pengetahuan dan keterampilan, sekaligus mengintegrasikan penanaman nilai-nilai karakter pada peserta didik melalui proses pembelajaran. Pembentukan nilai karakter yang dapat dimaksimalkan pada kegiatan ini adalah nilai kerjasama, kerja keras, kepedulian, dan kemandirian.

Dalam kegiatan elaborasi, guru PJOK memberikan peluang kepada peserta didik untuk memperluas dan memperdalam pengetahuan dan keterampilan yang diperoleh melalui kegiatan pembelajaran dan sumber belajar sekaligus memvisualisasikan nilai-nilai karakter yang telah ditanamkan pada kegiatan sebelumnya. Nilai-nilai karakter yang akan dikembangkan dan ditanamkan kepada peserta didik adalah nilai tanggung jawab, kejujuran, beradab, dan respek.

Kegiatan konfirmasi merupakan tahap dimana guru PJOK melakukan umpan balik (feedback) selama proses pembelajaran berlangsung. Inti dari kegiatan ini antara lain melakukan koreksi dan evaluasi selama proses kegiatan eksplorasi dan elaborasi sebelumnya. Pada kegiatan ini, nilai karakter yang dapat ditanamkan pada siswa meliputi percaya diri, koreksi diri, tanggung jawab, dan kejujuran.

\section{3) Evaluasi}

Tahap evaluasi mencakup tahap perencanaan dan pelaksanaan pembentukan karakter peserta didik yang terutama difokuskan pada proses dan hasil. Pada tahap ini Guru PJOK mengukur sejauh mana keberhasilan penanaman nilai-nilai karakter pada siswa sesuai dengan perencanaan yang telah disusun dan dilaksanakan sebelumnya. Pada tahap ini 
juga menganalisis hambatan-hambatan yang muncul selama pembentukan karakter siswa yang selanjutnya digunakan sebagai landasan untuk memperbaiki perencanaan pada siklus penanaman karakter selanjutnya. Instrumen yang digunakan untuk mengevaluasi dapat berupa lembar observasi; wawancara; maupun tes.

Untuk mempermudah dalam melaksanakan tahap-tahap di atas, beberapa bentuk strategi langsung dalam pembentukan karakter siswa yang dapat dilakukan selama proses pembelajaran PJOK di jenjang pendidikan dasar diantaranya:

1) Selama proses pembelajaran, tanamkan sikap sportif dan menghargai lawan lebih penting daripada suatu pencapaian.

2) Utamakan kejujuran sebagai sebuah nilai dalam pembelajaran pendidikan jasmani.

3) Berikan contoh dari kejujuran dan kebenaran. Jangan pernah minta siswa untuk berbohong.

4) Biasakan dan ajarkan siswa mengapresiasi dan menghargai peraturan suatu pertandingan/permainan

5) Tekankan pada siswa jangan berlaku kasar yang cenderung mencelakai lawan karena dapat menimbulkan luka serius bagi lawan atau bagi dirinya sendiri.

Proses pembentukan karakter tidak dapat dilaksanakan secara instan tetapi dibutuhkan sebuah proses dan kesabaran, keuletan dan waktu yang panjang, metode yang tepat, serta penggunaan teknik dan strategi yang sesuai. Banyak cara cara untuk mewujudkan keberhasilan pembentukan karakter, salah satunya melalui mata pelajaran pendidikan jasmani, olahraga, dan kesehatan. ${ }^{35}$ Dalam konteks pembentukan karakter siswa pada jenjang pendidikan dasar, strategi yang diimplementasikan pada pembelajaran PJOK sangat direkomendasikan karena pembelajaran ranah afektif akan lebih optimal.

\section{Kesimpulan}

Berdasarkan hasil penelusuran dari beberapa sumber literasi di atas, maka dapat disimpulkan :

1) Pembentukan karakter siswa melalui pendidikan karakter dapat dioptimalkan pada jenjang pendidikan dasar dengan memperhatikan beberapa prinsip antara lain : 1). Nilai-nilai Moral Universal; 2). Holistik; 3). Terintegrasi; 4). Partisipatif; 5). Kearifan Lokal; 6).

\footnotetext{
${ }^{35}$ Yandika Fefrian Rosmi, 'Pendidikan Jasmani Dan Pengembangan Karakter Siswa Sekolah Dasar', Wahana, 66.1 (2016), 55-61 <https://doi.org/10.36456/wahana.v66i1.482>.
} 
Kecakapan Abad XXI; 7). Adil dan Inklusif; 8). Selaras dengan Perkembangan Peserta Didik; 9). Terukur.

2) Pembentukan karakter siswa pada jenjang pendidikan dasar dapat dioptimalkan melalui mata pelajaran pendidikan jasmani, olahraga, dan kesehatan melalui sebuah proses yang berkelanjutan, metode pembelajaran yang tepat, serta penggunaan teknik dan strategi yang sesuai.

3) Membangun karakter peserta didik melalui pembelajaran pendidikan jasmani olahraga dan kesehatan dapat dilaksanakan dengan strategi inklusif. Strategi secara inklusif adalah model pendidikan karakter terintegrasikan pada semua materi yang dibawakan selama proses pembelajaran pada suatu mata pelajaran.

\section{Daftar Referensi}

Alnedral, Strategi Pembelajaran Pendidikan Jasmani, Olaharga Dan Kesehatan, 1st edn (Jakarta: KENCANA, 2016)

Basuki, Sunarno, 'Prosiding Seminar Nasional PS2DM UNLAM Vol. 2 No. 2 MANAJEMEN PENGELOLAAN PENJASKES BERBASIS KARAKTER DI SEKOLAH DASAR', 2.2 (2016), 72-77

Endriani, Dewi, Indah Verawati, and Andarias Ginting, 'Identifikasi Pembelajaran Pendidikan Jasmani Untuk Membentuk Karakter Siswa Sekolah Dasar', Jurnal Prestasi, 1.1 (2017), 1$5<$ https://doi.org/10.24114/jp.v1i1.6490>

Hidayati, Ninik, Nurul Hakim, and M. Zakki Sulton, 'PENDIDIKAN KARAKTER MELALUI PEMBIASAAN RUTIN UNTUK MENANAMKAN NILAI - NILAI PENDIDIKAN ISLAM PADA SISWA SD/MI', PREMIERE : Journal of Islamic Elementary Education, $2.2(2020), 47-61$

Kemdikbud, Kajian Dan Pedoman Penguatan Pendidikan Karakter (PPK), Kementrian Pendidikan Dan Kebudayaan Republik Indonesia, 2020 <https://cerdasberkarakter.kemdikbud.go.id/?wpdmpro=buku-konsep-dan-pedoman-ppk>

Marryono Jamun, Yohannes, 'Dampak Teknologi Terhadap Pendidikan', Jurnal Pendidikan Dan Kebudayaan Missio, 10.1 (2018), 48-52

Mustafa, Pinton Setya, 'Kurikulum Pendidikan Jasmani, Olahraga, Dan Kesehatan Di Indonesia Abad 21', Jurnal Pendidikan : Riset \& Konseptual, 4.3 (2020), 437-52 <https://doi.org/10.36765/jartika.v3i2.268>

Mutia, Merliza, Herita Warni, and Sarmidi Sarmidi, 'Peran Guru Pendidikan Jasmani Dalam Menanamkan Karakter Keapada Peserta Didik Di Sd Negeri Atu-Atu Kecamatan Pelaihari 
Kabupaten Tanah Laut', Multilateral Jurnal Pendidikan Jasmani Dan Olahraga, 18.2 (2019), 120-25 <https://doi.org/10.20527/multilateral.v18i2.7623>

Nugraha, Syafitri Agustin, 'KONSEP DASAR PENDIDIKAN KARAKTER', $A L$ MUNAWWARAH : Jurnal Pendidikan Islam, 8.2 (2016), 86-105

Nurmadiah, 'Konsep Dasar Pendidikan Karakter', Jurnal Al-Afkar, 6.2 (2018), 33-66

Pradana, Akhmad Aji, 'PENINGKATAN HASIL BELAJAR DENGAN METODE BERMAIN PERAN PADA MATA PELAJARAN BAHASA INGGRIS DI KELAS IV MI THORIQOTUL FALAH TALANGKEMBAR TAHUN PELAJARAN 2017/2018', PREMIERE : Journal of Islamic Elementary Education, 1.1 (2019), 1-17

Rosita, Lilis, 'PERAN PENDIDIKAN BERBASIS KARAKTER DALAM PENCAPAIAN TUJUAN PEMBELAJARAN DI SEKOLAH', JIPSi : Jurnal Ilmu Politik Dan Komunikasi, VIII.1 (2018), 1-26

Rosmi, Yandika Fefrian, 'Pendidikan Jasmani Dan Pengembangan Karakter Siswa Sekolah Dasar', Wahana, 66.1 (2016), 55-61 <https://doi.org/10.36456/wahana.v66i1.482〉

Rusmana, Adistia Oktafiani, 'PENERAPAN PENDIDIKAN KARAKTER DI SD', Jurnal Eduscience, 4.2 (2019), 74-80

Sukarmin, Yustinus, 'Membangun Karakter Peserta Didik Melalui Pembelajaran Pendidikan Jasmani Olahraga Dan Kesehatan', Seminar Nasional Pendidikan Olahraga 12 Mei 2012, 2012, 1-15

Susanto, Ermawan, 'Pembelajaran Pendidikan Jasmani Berbasis Karakter Untuk Meningkatan Nilai-Nilai Afektif Di Sekolah Dasar', Jurnal Pendidikan Karakter, 3.3 (2013), 288-301 <https://doi.org/10.21831/jpk.v0i3.2751>

Wahyuni, Rina, and Teti Berliani, 'Problematika Implementasi Kurikulum 2013 Di Sekolah Dasar’, Jurnal Manajemen Dan Supervisi Pendidikan, 3.2 (2019), 63-68 <https://doi.org/10.17977/um025v3i22019p063>

Widodo, Puput, and Ria Lumintuarso, 'Pengembangan Model Permainan Tradisional Untuk Membangun Karakter Pada Siswa SD Kelas Atas', Jurnal Keolahragaan, 5.2 (2017), 183 <https://doi.org/10.21831/jk.v5i2.7215> 